\title{
The Section and Board of Psychiatry of the Union of European Medical Specialists (UEMS): achievements and perspectives
}

1President, UEMS Section of Psychiatry, Rigshospitalet, Blegdamsvej 9, DK-2100 Copenhagen, Denmark, email lindhardt.a@rh.dk

2President, UEMS Board of Psychiatry

${ }^{3}$ Secretary UEMS, Section and Board of Psychiatry

he enlargement of the European Union (EU) creates new inspiration and challenges for the Section and Board of Psychiatry of the Union of European Medical Specialists (UEMS). The Section and Board, which have an active history dating back to the early 1990 s, aim to promote and harmonise psychiatry throughout Europe, mainly by working to produce standards for training, including conditions for training and continuous professional development (CPD). However, European society is complex and in transition. The move towards a more unified European professional identity first requires the identification and acknowledgement of differences.

\section{The UEMS}

The UEMS was created in 1958, following the Treaty of Rome. It is composed of a Management C ouncil, which has delegates appointed from 'the most representative non-governmental national professional organisation representing medical specialists' in each member state of either the EU or the European Free Trade Association (EFTA). A number of asso ciate member countries also send delegates. The overall purpose of the UEMS is to improve the quality of medical specialist practice in the EU. Thus, education is at the forefront of its activities. The U EMS mainly works on the formulation of policies, such as the Charter of Training, quality assurance, continuing medical education (CME), visits to training centres, and the autonomy of medical specialists. It works through consensus, as its function is advisory and not executive. In order to transform policies into practice guidelines, the UEMS has established mono-specialist Sections and Boards.

\section{The Section and Board of Psychiatry}

The Section has 15 countries as active full members (from both the EU and EFTA) and 12 countries as associate members, as well as observers from a number of closely linked organisations, such as the European Forum for Psychiatric Trainees (EFPT), the Permanent Working Group of junior doctors (PWG), the Association of European Psychiatrists (AEP), the World Psychiatric
Association (WPA) and the World Health 0 rganization (WHO). Each member country has two delegates appointed by its national medical association, representing the academic as well as clinical disciplines. The delegates represent their national psychiatric associations. However, whereas in some countries, such as the UK, only one national psychiatric asso ciation exists (the Royal College of Psychiatrists) which, therefore, has great influence on professional development and policy, in other countries, such as France, there are a number of associations involved in representing the specialist medical workforce and in training. This creates a diversity in the Section. In line with the policy of the UEMS, decisions are, wherever possible, based on consensus and can be reached only after consultation with the national associations. Although consensus is desirable, however, the UEMS acknowledges the need to reach decision by majority vote when consensus cannot be achieved.

\section{Achievements and challenges}

From the very beginning it was obvious that there were differences in structure, standards of training and even understanding of psychiatry as a discipline, not only between countries but also within the individual countries. Whereas in some countries, mainly in northern and western Europe, training was centralised according to national standards, in others standards were set at university level, in the absence of national standards. The role of the psychiatric associations in the formulation of training standards varied widely.

Thus, one of the first tasks of the Section was to create standards for training in line with contemporary knowledge, current developments and ethical issues. The training standards are published as chapter 6 in the U EMS charter on training (see below), and are revised every second year (the latest revision was approved in Berlin in 0 cto ber 2003).

The past 10 years have seen a great advance in training in all European countries and the standards established by the UEMS have proved their value. $N$ ational training standards have now been established in most European countries, and these take the recommendations of the UEMS charter as the basis for the development of curricula. The addition of eastern European countries has further

\section{One of the first tasks of the Section was to create standards \\ for training.}

\section{purpose of the \\ UEMS is to \\ improve the} quality of medical specialist practice in the EU. 
enhanced this development, since they have a need for proper tools for training and they wish to comply with a standardised programme.

The working methods of the Section have from the beginning consisted of identifying key issues, describing the state of art in the different countries through surveys and, based on this, achieving agreement on recommendations. Even though some compromises have had to be negotiated, the recommendations have mostly been understood as a means to improve standards, regardless of practical, economic and political difficulties. A key challenge has been to secure their implementation. An audit is now being carried out to get a clear picture of how far the recommendations are being followed.

\section{Charter on training}

The charter follows the structure established by the relevant U EM S policy paper. Its five articles relate to:

O a central monitoring authority for psychiatry, including quality assurance and personnel planning

o general aspects of training, including selection and access, duration, common basis, supervision, practical training and the use of a log book

o requirements for training institutions, including recognition, size of institutions and quality assurance

o requirements for teachers

o requirements for trainees.

In nine appendices, training is specified in the following terms (in relation to the surveys mentioned above):

o Theoretical training - in terms of number of hours and subjects to be covered. Here the diversity of the specialty is reflected, as training covers research, science, psychopathology, the theories and methods of treatment, legal, ethical and human rights perspectives, leadership, administration and economics.

o Training in psychotherapy (see below).

o Training in community psychiatry. At least 6 months of training is required as a member of a multi-disciplinary team. This is in order to gain experience both of work with patients outside hospital care and of social interventions.

o Training in biological psychiatry. This involves everything related to the pathophysiological substrate of the specialty.

o Old age psychiatry. This is an important multidisciplinary field involving joint work with physicians in medicine. In some countries this a sub-specialty while in others it is an integral part of adult psychiatry.

o Training in leadership and management. This deals, among other things, with goal formulation, how to motivate and work with patients and relatives, how to delegate and how to supervise staff. It also deals with planning, organisation, administration and the economics of a psychiatric service.

o The log book. This is a personal training file which includes a description of training activities and specific educational objectives.

o Supervision. Supervision is essential. There is a distinction between day-to-day clinical supervision and educational supervision. For the latter, regular protected time should be set aside, clear and preplanned objectives are required and a record of the content of supervision should be kept.

o Quality assurance. This implies that every training programme should have a defined goal, appropriate requirements for the training process and appropriate means for evaluation. This includes training as a lifelong learning process concerned with professional as well as personal develo pment.

The last appendix to the charter is a glossary that provides for a uniform understanding of the terminology used.

\section{Visits to training centres}

A small subcommittee was established in order to visit training centres upon request. Two visits in $H$ ungary and Slovenia were successfully concluded, but since this was rather costly, another model of attending as observers at approved visits by national visitation schemes was adopted. Thus, mutual visits between the UK and the $\mathrm{N}$ etherlands have taken place. A report on these visits states that extensive preliminary preparation is needed for each. In both countries, senior trainees are represented on the assessing panels and the trainees meet independently with the visiting team. Similar training issues were noted in both countries, such as tensions between training demands and training needs. Adequacy of supervision and access to psychotherapy training were also commonly discussed.

\section{Training in psychotherapy}

From the Section's beginning, psychotherapy was chosen as a core issue to the understanding of psychiatry as a specialty distinct from, but closely collabo rating with, other health professions. Also, psychotherapy was felt to be the treatment tool which most clearly distinguished psychiatry as being a part of, but also different from, the other neurosciences. In some countries, such as Germany, psychotherapy was not part of the specialty, whereas in other countries, such as Switzerland, the title of the specialty was psychiatry and psychotherapy. Recommendations for training in psychotherapy as an integral part of training in psychiatry were established early.

In the latest revision of the charter it is stated that psychotherapy is a tool for the treatment of patients with specific psychiatric disorders, as well as a tool for relieving emotional suffering and thus promoting personal development. Three main theories - psychodynamic, cognitivebehavioural and systemic - are still fundamental to the development of treatment interventions, even though a number of common factors have been identified and integrated therapies have evolved. Essentially, the understanding is that psychotherapy should be based on an established theory and empirically supported. Psychotherapy provides the tool for establishing and maintaining contact with the patient and maintaining the necessary therapeutic alliance. The question of the need for 
personal experience of therapy has been hotly debated; the agreement reached was that it is highly recommended but not mandatory.

\section{The CME/CPD Task Force}

Fruitful collaboration between the UEMS, W PA, AEP and WHO started in 2002. The problem of how to create a European supranational accreditation system has for some time been a key issue for a number of organisations. The UEMS established the European Accreditation Council for CME (EACC ME) in 2001 as a clearing house for accreditation and it has to some extent, but not through any transparent regulation, used the Sections in an advisory capacity. At the same time, other players started operating in the field of accreditation and without any clear affiliation were seeking links with national organisations. This was the background to the establishment of the Task Force on CME. The Task Force is seeking approval from national psychiatric organisations to start an independent accreditation system, free of any commercial and financial interests. The impression from several meetings with the presidents of national associations is that this idea is strongly supported.

\section{Recruitment and retention}

There is great concern over the issues of recruitment and retention. Psychiatry has for many years been a specialty low in hierarchy and in recent years a number of countries have seen a movement away from the less lucrative public sector to the private sector. This creates problems in terms of quality of service and of free and easy access to treatment. The Section has established a working group to investigate the attitudes of medical students towards psychiatry and to give recommendations on to how to increase the attractiveness of the specialty.

\section{Future perspectives}

Even though there are differences between the European countries in terms of demography, cultural diversity, service development, family structure and the degree of cultural changes due to migration, for example, the need to educate psychiatrists to encompass these differences and to apply uniform high ethical standards and high levels of qualified skills is increasing. The work of the UEMS Section and Board serves this purpose.

\section{Sources}

Hohagen, F. \& Lindhardt, A. (eds) (1997) Training in psychiatry in Europe. European Archives of Psychiatry and Clinical Neuroscience, 247 (suppl. 1).

Lindhardt, A. \& Saliba, J. (2001) Activities of the UEMS Section and Board of Psychiatry. In UEMS Compendium of Medical Specialities (1st edn, issue two), pp. 151-154. Available at ww w. uemspsychiatry.o rg/common/annualReports/ annual2000.pdf. Last accessed 29 April 2004.

Saliba, J. \& Katona, C. (2002) European Union of Medical Specialists - activities of the Section and Board of Psychiatry. Psychiatric Bulletin, 26, 224-227.

Strachan, J. \& Schudel, W. (2004) Accreditation of European training schemes in psychiatry. Psychiatric Bulletin, 28, 19-20.

\section{News and notes}

For contributions to this column, please contact Brian Martindale FRCPsych, Psychotherapy Department, John Conolly Wing, West London Mental Health NHS Trust, Uxbridge Road, Hanwell UB1 3EU, UK, email brian.martindale@wlmht.nhs.uk

\section{The Okasha Award for Developing Countries}

This award is presented by the World Psychiatric Association (WPA) via an unrestricted grant from APEX Pharma. It recognises the contribution of two young psychiatrists or neuroscientists (below the age of 40 ) whose research efforts have best served psychiatry and mental health in a developing co untry (as defined in categories B, C and D of the World Bank). Each award includes: a diploma, a medal and a donation of US $\$ 15000$. The two will be given by the President of the W PA, during the opening ceremony of the XIII World Congress of Psychiatry, Cairo, 10-15 September 2005. The breadth of criteria and a nomination form can be found on the W PA website www.wpanet.org/generalinfo/oaw ard.html. The closing date is $1 \mathrm{~N}$ ovember 2004.

\section{The Prize of Geneva for Human Rights in Psychiatry}

The prize is intended to acknow ledge an individual or an organisation, for exceptional achievement at regional, national or international level in promoting equity and the humane qualities of care for people with mental illness, reducing the negative discrimination of the mentally ill, defending the rights of people with mental illness, and promoting the application of ethical principles in psychiatric services. 